During last year the number of tests made in the engineering and physics departments was 1,330 , and the fees received amounted to $£ 350$, a sum of $£ 536$ being also received for researches undertaken in the laboratory; in the nine months of 1902 during which those departments were open the tests numbered only 269 and the fees were $\$ 69$. In addition, many applications were made for tests which the laboratory was unable to undertake, owing to lack of equipment; among these were tests on wire and wire ropes, on rubber, on the tensile strength of metals after special hardening, on cement and stone, on very high-speed anemometers, and on alternate-current instruments of all kinds. In the engineering department the need of a powerful testing machine was greatly felt, and work had constantly to be declined which would have been accepted if such a machine had been available.

But while the work of the laboratory has prospered, its financial position gives rise to grave anxiety. The receipts for 1903 were $£ 10,200$ and the expenditures $£ 10,306$, the deficiency thus being $£ 106$. In the preceding year the receipts were $£ 9,314$ and the expenses $£ 9,235$, the balance being $£ 79$. In addition, $£ 1,036$ was spent in 1903 on equipment out of the accumulations transferred from the Kew committee. Thus the laboratory is spending more than its income, and in the opinion of the executive committee a further increase of expenditure will be necessary in the present year. By drawing on the available balance of $£ 2,379$ it will be possible to go on for another year, but the committee feels that the time has come when the financial position must be reconsidered. This is the more necessary since the period for which the grant of $\$ 4,000$ was originally made ends next September, though the Royal Society has arranged with the treasury that it shall continue till April, 1905, and that a scheme for the future shall be considered by the treasury. The committee holds that an increase of funds is necessary even to maintain the work as at present, and a further increase of work for which there is a demand is to be carried out. It also thinks that, for the sake of permanence, the positions of the senior members of the staff should be made more secure, and that the stipends now paid to the assistants-with one exception $£ 200$ a year-are not commensurate with the work and are insufficient to retain for long the services of suitable men, while in addition the staff is now too small. It points out that similar institutions in other countries obtain more assistance from the state; in particular, the Reichsanstalt in Berlin alone gets $£ 16,000$, and the annual grants to the various institutions at Charlottenburg, which together cover the ground covered by the National Physical Laboratory, comes to about $£ 40,000$.

\section{THE BERMUDA BIOLOGICAL STATION FOR RESEARCH.}

HaRvard University and New York University again unite with the Bermuda Natural History Society in inviting zoologists and botanists to spend six weeks in the temporary biological station located, as last year, at the Flatts, Bermuda.

Venerable George Tucker, Archdeacon, president of the Bermuda Natural History Society.

Hon. W. Maxwell Greene, Consul U. S. A., vicepresident of the Bermuda Natural History Society.

F. Goodwin Gosling, honorary secretary of the Bermuda Natural History Society.

E. L. Mark, director of the Zoological Laboratory, Harvard University.

C. L. Bristol, professor of biology, New York University.

The Bermuda Islands are about seven hundred miles southeast of New York. They are nearly due east from Savannah, due south from Halifax, and due north from Porto Rico, being about equidistant from these three points. Since their discovery, in the seventeenth century, they have belonged to Great Britain, which maintains an important naval and military station there.

The climate is mild during the whole year, not being subject to the extremes that are found either in the temperate or tropical regions. The summer temperature is rarely higher than $85^{\circ} \mathrm{F}$., and the winter rarely below $50^{\circ} \mathrm{F}$. In the summer light breezes are almost constant and help to make the climate quite as comfortable as at many seaside resorts. 
The soil is very porous, so that there are no streams, all the fresh water used in the islands being rain water caught on whitewashed stone roofs and stored in covered cisterns. Endemic malaria and tropical fevers are unknown. The roads are excellent, and bicycles are much used.

The marine fauna and flora are abundant and such as are characteristic of coral reefs. The experience of last summer shows that there are available for study a great many varieties of marine forms, and that most of them occur in great abundance. The plan adopted in 1903 of recording the precise locality in which different organisms were found will greatly aid the investigator in procuring such material as he may desire.

Bermuda is reached in about sixty hours from New York by the vessels of the Quebec S. S. Co., which leave pier No. 47, North River, foot of West Tenth Street. During June, July and August, S. S. Trinidad is scheduled to sail from New York on the following dates: June 4, June 18, July 2, July 16, July 30, August 13; and returning to leave Hamilton, Bermuda, on June 11, June 25, July 9, July 23, August 6, August 20 and September 3.

By special arrangements with the Quebec S. S. Co., and the Hotel Frascati, the total expense of transportation from New York and return, and for board and lodging-but not washing-for six weeks at Bermuda, will be one hundred dollars. Board and lodging in excess of the period of six weeks will be charged for at the rate of ten dollars per week, but no arrangement will be made for a period of less than six weeks. This price is based on the understanding that two persons will occupy a room together. The payment of one hundred dollars entitles the applicant to the privileges of the laboratory and ample facilities for collecting and studying the animals and plants of the coral reefs, lagoons and shores.

The laboratory is a new and well-constructed building, and is furnished with all the ordinary glassware, reagents and apparatus provided in modern marine laboratories; but microscopes, dissecting instruments, slides and coverglasses are not supplied by the station. The means of collecting include a steam launch forty-five feet long and crew, a fishwell sailboat and crew, row-boats, a two-horse carriage carrying ten or twelve persons, nets, seins, water glasses, towing and dredging apparatus, etc.

The postoffice address of the station is Flatts, Bermuda.

Zoologists and botanists who desire to take advantage of the opportunities offered by the station should send applications as early as possible, and not later than June 1, either to Professor E. L. Mark, 109 Irving Street, Cambridge, Mass., or to Professor C. L. Bristol, New York University, University Heights, New York City. Applicants not officially connected with any scientific institution, or with any university or college in the capacity of instructors, should send letters of endorsement from those under whom they have studied. Applications should in all cases state the nature of the work proposed, and if possible the precise problem or problems contemplated. It will be possible in some cases to provide the use of books and monographs, if applicants indicate those which they desire but can not themselves procure. It should be understood that the opportunities offered are for investigations and that no formal instruction will be given. Each application should be accompanied with the sum of fifty dollars. If the application is accepted, a ticket and state-room assignment will be promptly forwarded to the applicant. Otherwise the fifty dollars will be returned. The remaining fifty dollars is to be paid upon arrival at Bermuda. No reduction from the sum named (one hundred dollars) can be made for any cause.

The date of sailing from New York is July 2. If a change in this date is necessitated by any change in the schedule of the Quebec S. S. Co., timely notice will be sent to every applicant.

Biologists who intend to take away from Bermuda collections, should ship to Bermuda their own alcohol, formol and cans for transporting specimens. Tax-free alcohol can be exported from the United States, a certificate of landing in Bermuda being all that will be 
required in addition to the dealer's bond. The Quebec S. S. Co. agrees to charge for transportation only one-half its regular tariff rate on all scientific collections, apparatus, equipment, etc., both from New York to Bermuda and from Bermuda to New York.

Drafts on New York, gold coin and bank notes are current in Bermuda at $\$ 4.80$ to the pound sterling; silver coin is not current.

If further information is desired, inquiries may be addressed to either of the undersigned.

$$
\begin{array}{ll} 
& \text { E. L. Mark, } \\
\text { April } 1,1904 . & \text { C. L. BRISToL. }
\end{array}
$$

SCIENTIFIC NOTES AND NEWS.

$\mathrm{A}_{\mathrm{T}}$ the meeting of the National Academy of Sciences last week members were elected as follows: Professor William Morris Davis, Harvard University; Professor William Fogg Osgood, Harvard University; Professor William T. Councilman, Harvard Medical School; Professor John U. Nef, University of Chicago. The foreign associates elected were: Professor Paul Ehrlich, Frankfurt; Professor H. Rosenbusch, Heidelberg; Professor Emil Fischer, Berlin; Sir William Ramsay, London; Sir William Huggins, London; Professor George H. Darwin, Cambridge; Professor Hugo de Vries, Amsterdam; and Professor Ludwig Boltzmann, Vienna. The Draper gold medal was presented to Professor George E. Hale, of the Yerkes Observatory, Wisconsin, for his researches in astrophysics.

THE Station for Experimental Evolution of the Carnegie Institution has established the class of associates including biologists of this country who are engaged in work in experimental evolution and who receive especial assistance from the Carnegie Institution or its station for this work. The station and its associates will work in a cooperative way, especially in the exchange of material for investigation. The following have become associates of the station for the year 1904: Professor N. L. Britton, New York Botanical Garden; Professor W. E. Castle, Harvard University; Professor H. E. Crampton, Columbia University; Professor D. T. MacDougal, New York Botanical Garden; Professor E. L. Mark, Harvard University; Pro- fessor W. J. Moenkhaus, Indiana University; Professor W. L. Tower, University of Chicago; Professor E. B. Wilson, Columbia University.

The Prussian gold medal for science has been presented to Professor Wilhelm Hittorf, the eminent physicist and chemist, on the occasion of his eightieth birthday.

M. C. E. Bertrand has been elected a corresponding member of the Paris Academy of Sciences in the section of botany.

Miss N. M. Stevens, A.B. (Stanford), Ph.D. (Bryn Mawr), has been appointed Carnegie research assistant and reader in experimental morphology at Bryn Mawr College.

Associate Professor George C. Price, of the department of physiology of Stanford University, who has been in Europe on his sabbatical leave of absence, recently arrived in Boston, where he will spend the next three months at work in the embryological laboratory of Professor C. S. Minot of the Harvard Medical School.

Professor G. N. Calukins, of Columbia University, will spend the summer abroad, visiting zoological laboratories.

Mr. Raymond S. Dugan, formerly assistant to Professor Todd, in Amherst College Observatory, later for three years in charge of the Beyrout Observatory and now assistant to Dr. Max Wolf in Heidelberg, has discovered a new planet which he has named Amherstia, in honor of his Alma Mater. Mr. Dugan graduated at Amherst College in 1899.

THE annual congress of French learned societies met at the Sorbonne, Paris, beginning on April 5. M. Levasseur presided.

The congress of the French societies of geography was held at the beginning of the present month at Tunis under the presidency of M. Pichon.

Dr. Bowdler Sharpe, of the British Natural History Museum, has lately returned to England with some rare specimens of birds from the Cayman Islands.

Dr. M. Mryajima, instructor in the Imperial Hygienic Institute of Tokyo, has reached St. Louis to supervise the installation of the ex- 